\title{
Isolation of Single Spore and Identification of Resistance against Soybean Anthracnose
}

\author{
Tamin*, A.S. Kotasthane, N. Khare and Vivekanand Uraiha \\ Department of Plant Pathology, IGKV, Raipur (CG) 490 012, India \\ *Corresponding author
}

\section{A B S T R A C T}

\begin{tabular}{|l|}
\hline Ke y w o r d s \\
Soybean, Single \\
spore, \\
Colletotrichum, \\
Resistance
\end{tabular}

\section{Introduction}

Soybean (Glycine max L. Merill) is a species of legume native to East Asia. The plant is classed as an oilseed rather than a pulse. Soybean is one of the world's most important sources of oil and protein. It has highest protein content among leguminous crops belonging to the family leguminaceae. Besides its economic value, it is highly nutritious food to human being as its 40 per cent protein content, 20 per cent carbohydrates and 23 per cent oil, holds a great promise in meeting most of the need in human diet (Chandel, 2002). Soybean contains valuable amino acids. In addition, it contains a good amount of minerals $(\mathrm{Ca}, \mathrm{Mg}$, $\mathrm{P}$ and $\mathrm{Fe}$ ), salts and vitamins (Thiamine and Riboflavin and D), hence called 'poor man's meat'.

In Chhattisgarh, research work on important aspects of the anthracnose disease of soybean. Information on crop loss assessment, epidemiological studies and integrated disease management strategies are lacking. A number of management approaches viz., use of tolerant varieties, application of fungicides, cultural practices and combination of approaches leading to integrated management of the disease have been evaluated. It is necessary to know the severity of the disease 
and factors associated with disease. Host plant resistance is considered as most practical, feasible and an economical method of plant disease management. Generally in soybean, the disease is severe in more prevalent at all stages of development particularly from bloom to pod fill. Raddish brown spot appears on the pods and later they turn black. Fruiting bodies (Acervulli) on infected pods resemble small pin cushions surrounded by minute blackish brown setae (Han et al., 1995). The disease causes considerable damage by reducing plant stand, seed quality, seed germination and yield (Rodriguez and sinclair 1978).

The only practicable and cost-effective control for such a devastating seed-borne pathogen is selection of cultivars. Therefore, the present study was conducted to screen the soybean entries for the identification of resistant sources.

\section{Materials and Methods}

\section{Single spore isolation and maintenance of culture}

Colletotrichum spp. will be isolated from the different naturally infected hosts collected from Raipur (C.G.). Single spore which were spread on $4 \%$ water agar, after germination will be directly picked using capillary needle and transferred on PDA slants. Purified isolates will be maintained on water agar slants at $26 \pm 1^{\circ} \mathrm{C}$ in BOD incubator for further use.

\section{Screening of soybean entries under natural conditions}

A field experiment was conducted to know the resistance levels in soybean entries during 2017-18. All the agronomic practices were followed except plant protection measures. The severity of pod blight was recorded at beginning of the maturity using a disease rating scale 0 to 9 given by Mayee and Datar (1986). Thereafter per cent disease index (PDI) was calculated.

Per cent disease index $=$

Sum of all disease rating $\times 100$

Total no. of rating $\mathrm{x}$ Maximum disease grade

On the basis of PDI calculated the germplasm was categorized as mentioned below.

\section{Results and Discussion}

\section{Procedure for isolation of single spore progenies}

Observing an acervuli, under the Nickon stereobinocular microscope spores were picked using an fine pointed capillary needle. Spores were then placed on the $4 \%$ water agar. Using a bent fine capillary glass needle the spores were then separated as far as possible from each other. The plates were then incubated at $27^{\circ} \mathrm{C}$ for $4-6 \mathrm{hr}$. to allow the spores to germinate. The germ tube was allowed to proliferate and penetrate the agar.

Observing an isolated germinating spore under the Nickon stereobinocular microscope, agar surrounding the germinating was cut using a sterilized fine pointed inoculation needle (pony No. 12). The agar block containing a single germinating spore was then aseptically transferred to the Potato Agar slants and incubated at $27^{\circ} \mathrm{C}$. Efficiency of isolation of single spore was almost $100 \%$ by this method. By this procedure in a single attempt as many as 60-80 spore could be obtained. In 3-4 days at $27^{\circ} \mathrm{C}$ growth appeared on Potato dextrose agar slants. The sequences of steps involved in single spore isolation are depicted in fig.1. Genetic analysis, tagging, mapping and isolating the 
gene are specialized approaches and essentially require isolating microorganisms in pure form or genetically pure form. It is possible to isolate different microorganisms by enrichment technique but require an inordinate amount of time, labour, and money. Medium selection, diluents, incubation conditions, and sample handling determine the number and types of microorganisms from plant, soil, and water (Hansen, 1926; Hildebrand, 1938; Collins et al., 1977; Choi et al., 1999; Gupta et al., 2011). Therefore, what is isolated from the defined ecosystem or for a defined specialized approach is a reflection of the isolation procedure and conditions set by researcher. The conventional method of isolating well separated spores streaked on the agar medium under a stereoscopic microscope was used by Tuite (1969). Kumar et al., (2007) reported a technique for monoconidial culture of the most aggressive isolate in a given population of Bipolaris sorokiniana, to facilitate the evaluation of spot blotch resistance in wheat and barley.

The efficiency of single spore isolation representing a true mitotic event by the proposed method is almost cent percent and justifies the generation of genetically pure population ( $>90$ progenies) for specialized approaches in a single attempt. The increased size of the micro-spore due to wellproliferated germ-tube is the basis of this technique (Table 1 and 2).

Table.1 Genotype categorization based on rating

\begin{tabular}{|c|c|c|l|}
\hline $\begin{array}{c}\text { S.N } \\
\text { o }\end{array}$ & Grade & $\begin{array}{l}\text { Per cent disease } \\
\text { incidence(PDI) }\end{array}$ & Category Reactions \\
\hline $\mathbf{1}$ & 0 & $0-5$ & Highly resistant \\
\hline $\mathbf{2}$ & 1 & $6-10$ & Resistant \\
\hline $\mathbf{3}$ & 3 & $11-25$ & Moderately resistant \\
\hline $\mathbf{4}$ & 5 & $26-50$ & Moderately susceptible \\
\hline $\mathbf{5}$ & 7 & $51-75$ & Susceptible \\
\hline $\mathbf{6}$ & $\mathbf{9}$ & $\mathbf{7 6 - 1 0 0}$ & Highly susceptible \\
\hline
\end{tabular}

Table.2 Reaction of soybean genotypes to C. truncatum under natural conditions during 2017-18

\begin{tabular}{|c|c|c|c|}
\hline S.No & Score & Disease Reaction & Genotypes \\
\hline 1 & 0 & Highly Resistant & NIL \\
\hline 2 & 1 & Resistant & $\begin{array}{l}\text { IVT-04,RSC-10-52, TMAS-38, IVT-39, IVT-26, IVT-24, RSC-10- } \\
\text { 71, NRS-125, IVT-13, RSC-10-70 }\end{array}$ \\
\hline 3 & 3 & $\begin{array}{l}\text { Moderately } \\
\text { resistant }\end{array}$ & $\begin{array}{l}\text { RSC-10-46, NRC-7, CG-SOYA-1, JS(SH)2003-2, IVT-2, JS-20- } \\
\text { 19, IVT-37, IVT-7, IVT-5, MAVS-612, AMS-323, IVT-40, NRC- } \\
\text { 82, JS-20-39, KDS-354, IVT-19, KS-3, IVT-34, IVT-10 }\end{array}$ \\
\hline 4 & 5 & $\begin{array}{l}\text { Moderately } \\
\text { susceptible }\end{array}$ & $\begin{array}{l}\text { KDS-344, IVT-27, IVT-33, IVT-15, IVT-38, IVT-8, IVT-30, } \\
\text { IVT-17, IVT-20, IVT-21, IVT-43, IVT-32, PS-1477, IVT-42, IVT- } \\
\text { 24, JS-20-34, IVT-16, IVT-35 }\end{array}$ \\
\hline 5 & 7 & Susceptible & IVT-25, IVT-41, IVT-28, IVT-39, IVT-1 \\
\hline 6 & 9 & $\begin{array}{l}\text { Highly } \\
\text { Susceptible }\end{array}$ & $\begin{array}{l}\text { IVT-29, IVT-36, IVT-6, IVT-2, IVT-3, IVT-4, IVT-18, IVT-11, } \\
\text { IVT-12, IVT-9, IVT-31, IVT-13 }\end{array}$ \\
\hline
\end{tabular}


Fig.1 Single spore isolation technique followed
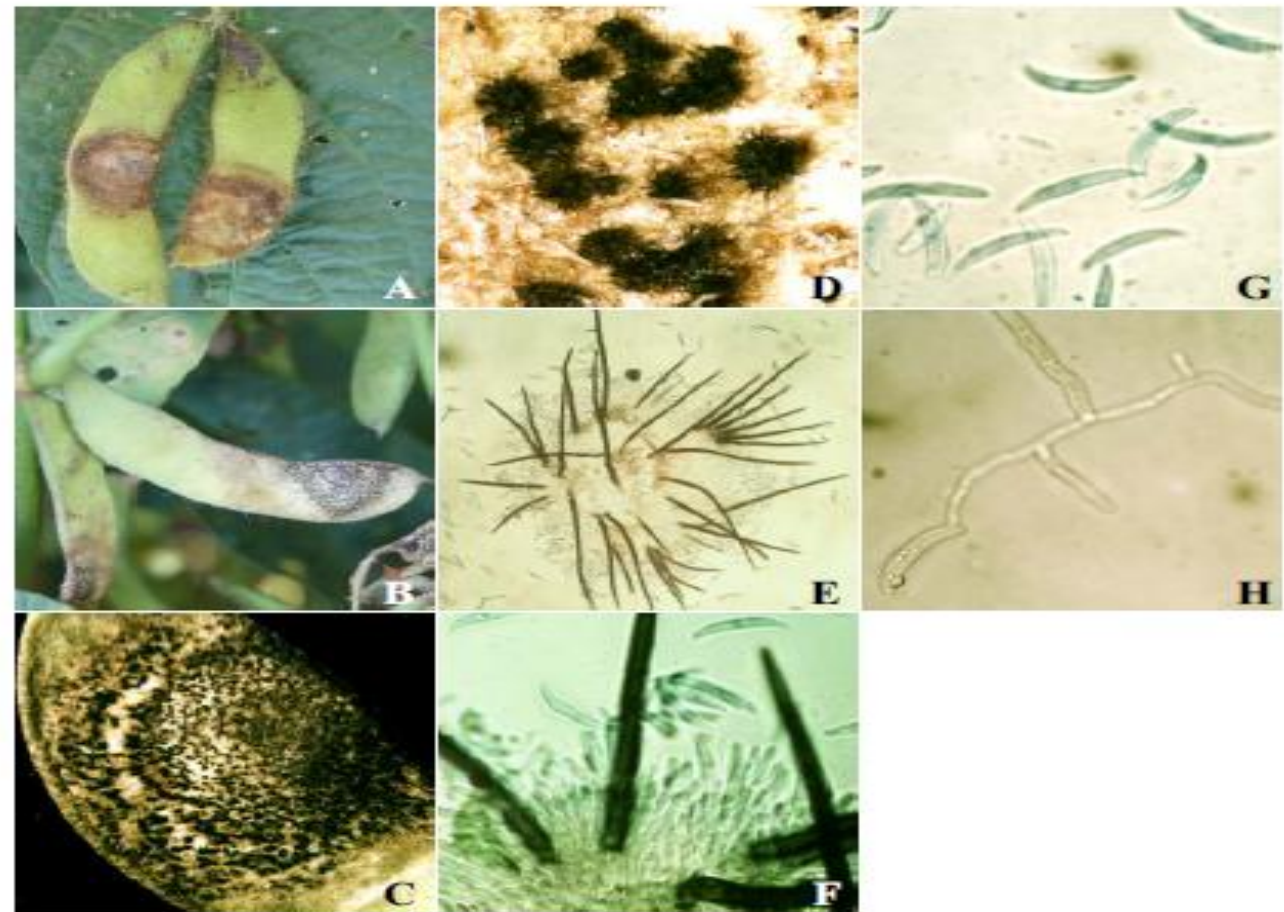

Fig.2 Resistant and susceptible phenotypes observed during screening of soybean genotype against pod blight

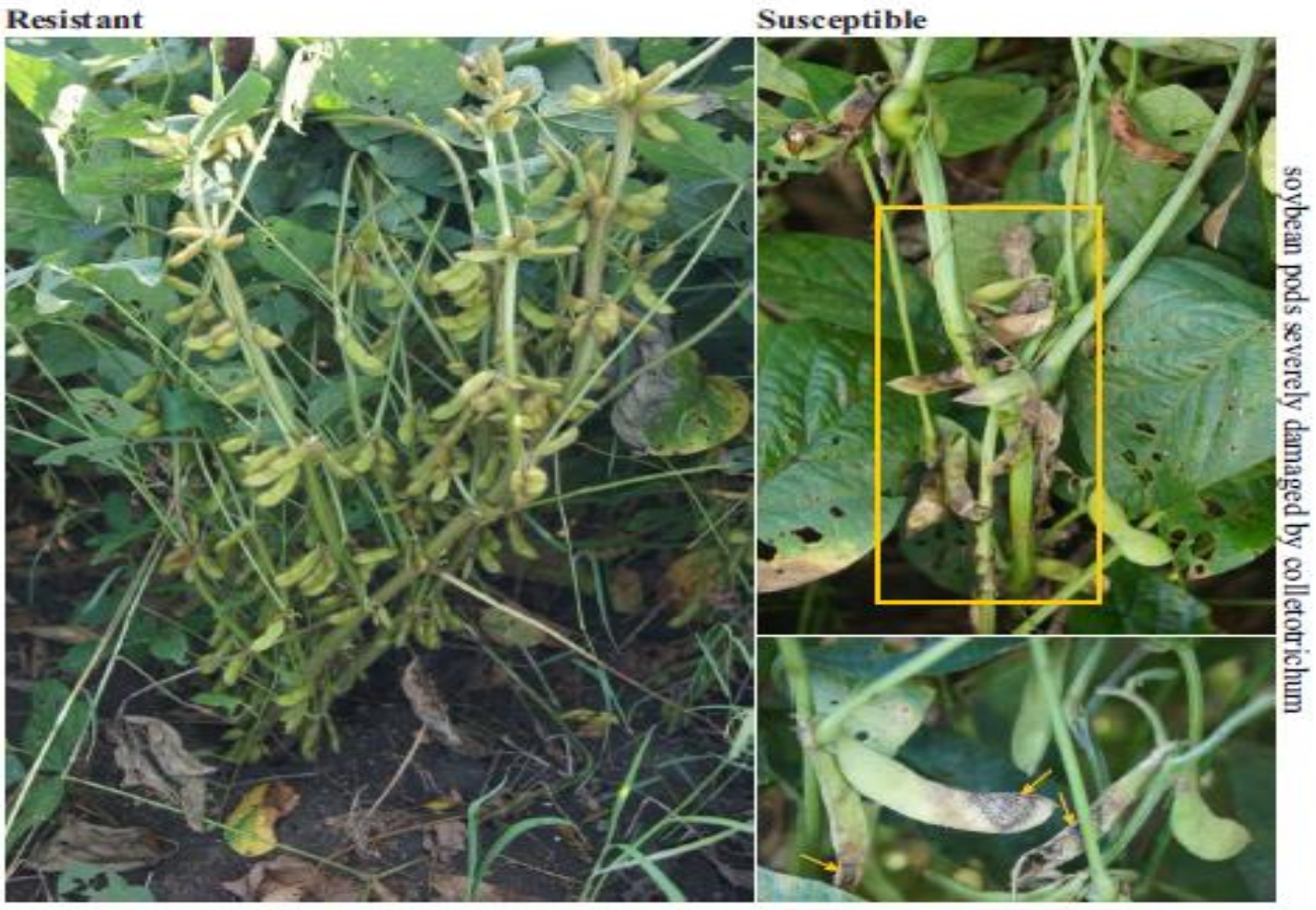


One can be very certain that the spore being isolated is clearly discernable and directly lifted from the source and the minimized use of water justifies the procedure to be direct, simple and rapid.

\section{Screening of genotypes for their resistance to pod blight under natural conditions during 2017-18}

Anthracnose of soybean was first reported from Korea in 1917, but now occurs in all soybean-growing areas. The disease can cause 16 to 100 per cent losses in yield depending upon the cultivar and environmental conditions. The infected pods either have very small, shriveled, brown, moldy seeds or produce no seed. Anthracnose of soybean can be managed by the use of resistant varieties, clean cultivation, and pathogen-free seeds. In the present investigation 138 soybean entries were evaluated for anthracnose resistance during the wet season of 2017-18. Evaluation for anthracnose resistance indicated no immune genotype, 10 genotypes (IVT-24, IVT-26, IVT-39, TMAS-38, RSC-10-52, IVT-04, RSC-10-70, IVT-13, NRS-125, RSC10-71) were classified as resistant (Score1) and 12 as highly susceptible. Rest of the 116 entries were evaluated MR to Susceptible group. There are few studies that have evaluated anthracnose resistance in soybean. Several studies reported on the evaluation of 414 soybean germplasm accessions to $C$. truncatum (Manandhar et al., 1986 a \& b; Manandhar et al., 1988; Hossain et al., 2001). These studies found no immune genotypes; however, 10 genotypes were classified as resistant. Breeding efforts to produce anthracnose-resistant soybean cultivars are lacking despite the potential for yield losses due to this disease. In addition, there is a lack of knowledge about soybean resistance in different tissues (from roots to seed) and whether any described resistance would be effective against the several species of
Colletotrichum that cause anthracnose. The soybean genotype Mandarin was among the soybean genotypes reported to have resistance to anthracnose (Manandhar et al., 1986 a \& b). Ten genotypes which were classified as resistant in our present investigation will be reconfirmed following recently reported artificial inoculation technique to screen soybean for resistance to anthracnose by Yang and Hartman (1986). Several lines of evidence indicate screening of soybean genotypes for resistance to anthracnose of soybean. Gawade et al., (2009) reported that out of 184 soybean genotypes, 109 genotypes were expressed moderately resistant reaction, whereas Madhusudhan (2002) reported 27 moderately resistant genotypes out of 60 screened against $C$. truncatum. Similarly seven out of 16 soybean varieties expressed resistant reaction under natural conditions (Khalko 2011; Kaushal and Paul 1991).

\section{References}

Chandel, A.S., 2002. Soybean Cited from textbook of field crops production. ICAR, pp. 372-396.

Choi, Y.W., Hyde, K.D. and Ho, W.H. 1999. Single spore isolation of fungi. Fungal Diversity 3: 29-38.

Collins, M. D., Pirouz, T., Goodfellow, M. and Minnikin, D. E.1977. Distribution of menaquinones in actinomycetes and corynebacteria. J. Gen. Microbiol. 100, 221-230.

Gawade, D. B., Suryawanshi, A. P., Patil, V. B., Zagade, S. N. and Wadje, A. G. 2009. Screening of soybean cultivars against anthracnose caused by Colletotrichum truncatum. Journal of Plant Disease Sciences, 4(1):124-125.

Gupta, B., Reddy, N. P. N. and Kotasthane, A. S. 2011. Molecular characterization and mating type analysis of oyster mushroom (Pleurotus spp.) using single basidiospores for strain improvement. 
Journal of Microbiology and Biotechnology, 27: 1-9.

Han, K., Sook, L. and Du, H. 1995. Identification and etiological characteristics of anthracnose fungi isolated from soyabean, adzuki beans and mung beans. Korean. J. Pl. Pathol., 11: 30 .

Hansen, H.N. 1926. A simple method of obtaining single-spore cultures. Science, 64: 384 .

Hildebrand, E.M. 1938. Techniques for the isolation of single microorganisms. Botanical Review, 4: 627-664.

Hossain, I., Islam, M. R. and Hamiduzzaman, M. M. 2001. Screening of soybean germplasms for resistance against Colletotrichum truncatum infection. Pakistan Journal of Scientific and Industrial Research, 44 (5): 305-307.

Kaushal, R. P. and Paul, Y. S. 1991. Field evaluation of soybean germplasm against pod rot. Plant Disease Research, 6(2): 82.

Khalko, S. 2011. Studies on Colletotrichum truncatum (Schw.) Andrus and Moore the incitant of soybean anthracnose disease. M.Sc. Thesis, Indira Gandhi Krishi Vishwavidyalaya, Raipur.

Kumar, D., Chand, R., Prasad, L.C. and Joshi, A.K., 2007. A new technique for monoconidial culture of the most aggressive isolate in a given population of Bipolaris sorokiniana, cause of foliar spot blotch in wheat and barley. World Journal of Microbiology and Biotechnology, 23(11): 1647-1651.

Madhusudhan, B. S. 2002. Studies on soybean anthracnose caused by Colletotrichum truncatum (Schw.) Andrus and Moore. MSc (Agri.) Thesis, Univ. Agril. Sci., Dharwad. pp.78-82.

Manandhar, J. B., Hartman, G. L., and Sinclair, J. B. 1986. Biol. Cult. Tests Control Plant Dis., 1:32.

Manandhar, J. B., Hartman, G. L., and Sinclair, J. B. 1986. Biol. Cult. Tests Control Plant Dis., 1:33.

Manandhar, J. B., Hartman, G. L., and Sinclair, J. B. 1988. Plant Dis., 72:5659.

Mayee, C.D. and Datar, V.V., 1986. Phytopathometry.

Rodriguez and sinclair 1978. Fruiting structures of Colletotrichum truncatum and Phomopsis sojae formed in soybean seeds. Pl. Dis. Report. 62: 873-876.

Tuite, J. 1969. Plant Pathological MethodsFungi and Bacteria. Burgess Publ. Co., Minneapolis, Minnesota, pp. 239.

Yang, H.C. and Hartman, G. L. 1986. Methods and Evaluation of Soybean Genotypes for Resistance to Colletotrichum truncatum. Plant Disease and Protection, 99(1): 143-148.

\section{How to cite this article:}

Tamin, A.S. Kotasthane, N. Khare and Vivekanand Uraiha. 2019. Isolation of Single Spore and Identification of Resistance against Soybean Anthracnose. Int.J.Curr.Microbiol.App.Sci. 8(06): 1259-1264. doi: https://doi.org/10.20546/ijcmas.2019.806.153 